\title{
What Daphne wrote Georgia
}

\section{Trish SALAH}

Trish Salah (salahp@yorku.ca) is a doctoral student in the English Department at York University. Her dissertation engages questions of libidinal and rhetorical economy as they pertain to the representation of transgender figures and transsexual politics. She is the author of a collection of poetry, Wanting in Arabic (TSAR 2002).

(From Wanting in Arabic)

What a heart is, is forever at risk. Reborn to you, I know this, and to that condition, consent.

In your eyes, disclosed, a singular deprivation: your want is turned to passion, it is steeling.

And when we turn to boys, rare with thirst and trust that our becoming might remain ours

you threaten, giddy and rudely, you promise to devour me roughly, to take me wholly inside.

Under your mouth and in your hands, I become again, so protean as to survive that, more, to grow wild and lovely.

Beloved, consider a carefully cultivated flame.

Of how it is that I want, with you. 
168 / Salah

II

How shall we make our way between Jerusalem, Misra, Beirut? Before time falls upon time, loose sheaf of translucence.

Do not tell me the day is gone, and the night is gone; between them, love lies like a kiss, the word's cataclysm.

You avoid promises, warding curses, bad fortune. Your opacity is an achievement I should marvel at,

or, emulate. So the future might not notice, your touches are that light.

III

What now? You might ask or or I may, some may, wanting caution or

your glance, enduring this insistent remoteness, our common discourse:

the timeliness of friendship, or the banality of roses, of structures

of revenance or romance...Christ, How childish! We declaim, superior

too, and from our past selves, sundered.

Surrender, our best bet, for a future.

No, not in love, any thing but Any other thing will do. 


\section{IV}

I do not know how you came to dwell in this, a room as low as my heart to the ground.

I do not own this room, or, in your dwelling, a body with rumored tears, to comfort, to hold.

I do not own this tomb, or, pretend to. You, do I ask but your consent to be generous, with time?

How is it this room is filled with bodies? Their skins full up with sand. Forget that.

I do not know, if you came to bury here, whyCould we not leave the past the future, now? 